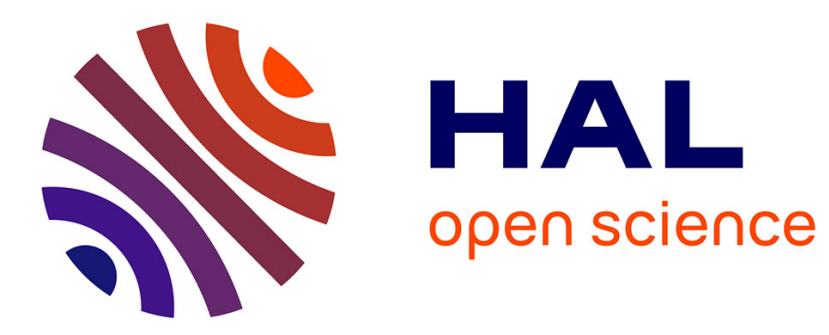

\title{
On ramp metering: Towards a better understanding of ALINEA via model-free control
}

Hassane Abouaïssa, Michel Fliess, Cédric Join

\section{To cite this version:}

Hassane Abouaïssa, Michel Fliess, Cédric Join. On ramp metering: Towards a better understanding of ALINEA via model-free control. International Journal of Control, 2017, 90 (5), pp.1018-1026. 10.1080/00207179.2016.1193223 . hal-01326514

\section{HAL Id: hal-01326514 \\ https://hal-polytechnique.archives-ouvertes.fr/hal-01326514}

Submitted on 3 Jun 2016

HAL is a multi-disciplinary open access archive for the deposit and dissemination of scientific research documents, whether they are published or not. The documents may come from teaching and research institutions in France or abroad, or from public or private research centers.
L'archive ouverte pluridisciplinaire HAL, est destinée au dépôt et à la diffusion de documents scientifiques de niveau recherche, publiés ou non, émanant des établissements d'enseignement et de recherche français ou étrangers, des laboratoires publics ou privés. 


\title{
On ramp metering: \\ Towards a better understanding of ALINEA via model-free control
}

\author{
Hassane Abouaïssa $^{a}$, Michel Fliess ${ }^{b, d}$, Cédric Join ${ }^{c, d, e}$
}

${ }^{a}$ Laboratoire de Génie Informatique et d'Automatique de

l'Artois (LGI2A, EA 3926),

Université d'Artois, 62400 Béthune, France

hassane . abouaissa@univ-artois.fr

${ }^{b}$ LIX (CNRS, UMR 7161), École polytechnique, 91128 Palaiseau, France

Michel.Fliess@polytechnique.edu

${ }^{c}$ CRAN (CNRS, UMR 7039), Université de Lorraine,

BP 239, 54506 Vandoeuvre-lès-Nancy, France cedric.join@univ-lorraine.fr

${ }^{d}$ AL.I.E.N. (ALgèbre pour Identification et Estimation Numériques), 24-30 rue Lionnois, BP 60120, 54003 Nancy, France

\{michel.fliess, cedric.join\}@alien-sas.com

${ }^{e}$ Projet NON-A, INRIA Lille - Nord-Europe, France. 


\begin{abstract}
ALINEA, which was introduced almost thirty years ago, remains certainly the most well known feedback loop for ramp metering control. A theoretical proof of its efficiency at least when the traffic conditions are rather mild is given here, perhaps for the first time. It relies on tools stemming from the new model-free control and the corresponding "intelligent" proportional controllers. Several computer experiments confirm our theoretical investigations.
\end{abstract}

\title{
Keywords:
}

Ramp metering, ALINEA, integral controllers, PIDs, proportional-integral controllers, model-free control, intelligent proportional controllers, lowpass filters, METANET. 


\section{Introduction}

The goal of ramp metering is to improve the highway traffic conditions by an appropriate regulation of the inflow from the on-ramps to the highway mainstream (see, e.g., [Agarwal et al.(2015), Kachroo et al.(2003), Mammar(2007), Papageorgiou et al.(2003)], and the references therein). Among the many feedback control laws which may be found in the huge literature devoted to traffic control, ALINEA (see, e.g., [Papageorgiou et al.(1991)])

- is one on the very few closed-loop control synthesis which has been implemented in practice,

- remains certainly the most popular one in spite of some criticisms (see, e.g., [Papageorgiou et al.(2007)], and the references therein).

An explanation of ALINEA's brillant success seems to be missing until today, although it might lead to improve the existing ramp metering technologies. This aim is fulfilled here by connecting ALINEA to classic PI controllers (see, e.g., [Åström et al.(2008)]), which play such a key rôle in industry. It is achieved thanks to the recent model-free control setting ([Fliess et al.(2013)]), which is

- able to cope with a large variety of concrete case-studies (see, e.g., [Abouaïssa et al.(2012)] for an application to ramp metering),

- becoming more and more popular (see, e.g., [Åström et al.(2014), Gao(2014), de Larminat(2009)]).

Among the intelligent controllers which are associated to model-free control, intelligent proportional controllers, or $i P \mathrm{~s}$, are the simplest and most useful ones. Our approach tells us that ALINEA is close to a PI, or an iP, if

- the reference trajectories do not exhibit a "violent" behaviour,

- the disturbances and corrupting noises are rather low.

Several computer experiments fully confirm the above theoretical investigations.

Our paper is organized as follows. A short presentation of ALINEA is provided in Section 2. Section 3 reviews model-free control and proves that ALINEA and intelligent proportional controllers are more or less equivalent when the traffic conditions are as explained a few lines before. Computer experiments are discussed in Section 4, where ALINEA and intelligent proportional controllers are compared. Some concluding remarks may be found in Section 5.

\section{ALINEA: A short presentation}

Ramp metering may be visualized via Figure 1 where

- $q_{r}$, in veh/s, is the ramp flow related to the control variable $r$,

- $w$ represents the queue length in vehicles,

- $d$, in veh/s, is the ramp demand,

- $q_{e}$, in veh/s, is the upstream segment flow, 


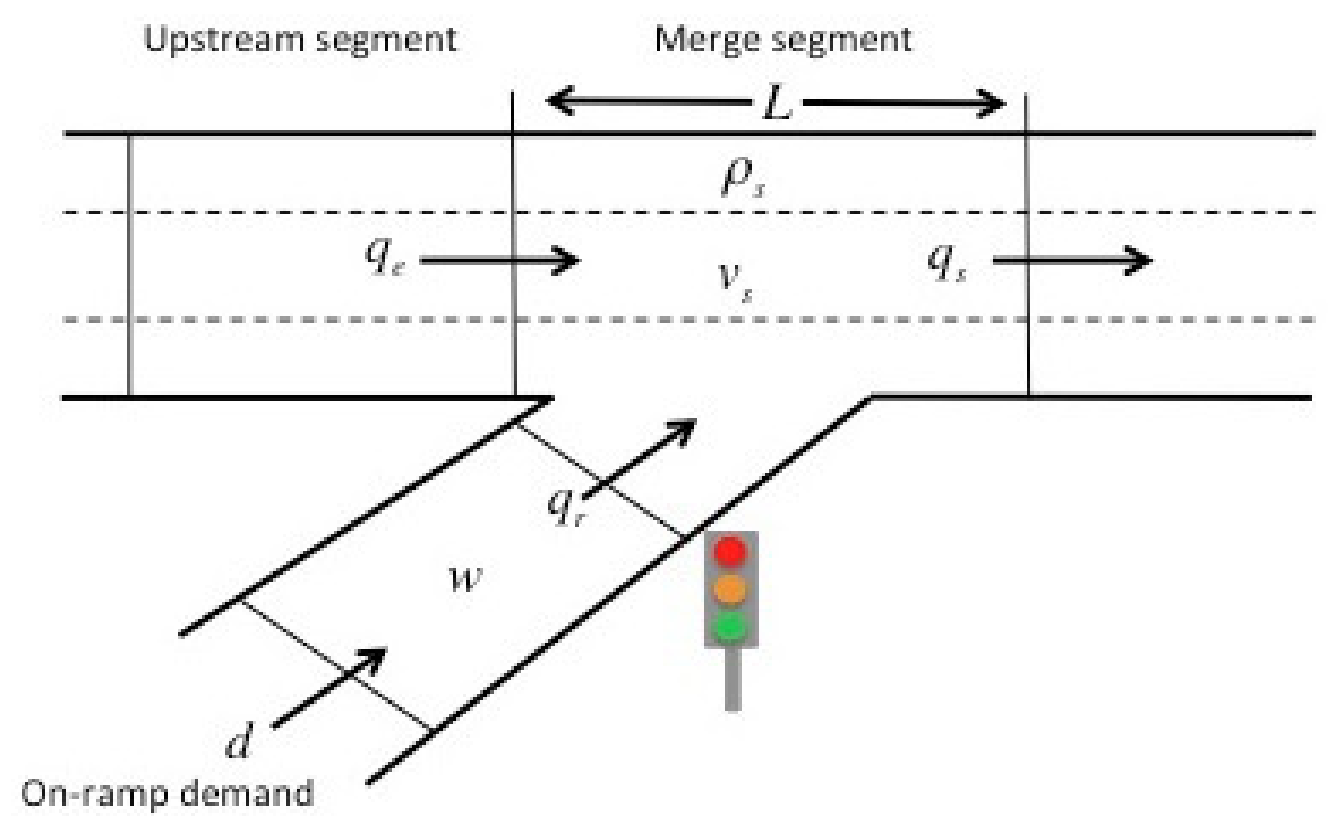

Figure 1: Highway ramp metering principle

- $q_{s}$, in veh/s, is the downstream segment flow,

- $\rho_{s}$, in veh $/ \mathrm{m}$, is the segment density,

- $v_{s}$, in $\mathrm{m} / \mathrm{s}$, is the segment speed.

The feedback loop defining ALINEA ${ }^{1}$ reads in discrete-time

$$
r(k)=r(k-1)+K_{I}\left(\rho^{\star}-\rho_{s}\right)
$$

where

- $r(k)$, which is the rate of ramp inflow (see Figure 1), stands for the control variable at time $k$,

- the gain $K_{I}$ is the only adjustment parameter,

- the segment density $\rho_{s}$ (see Figure 1) stands for the output variable,

- $\rho^{\star}$ is the reference trajectory.

Remark 2.1 ALINEA was introduced almost thirty years ago ([Haj-Salem et al.(1988), Haj-Salem et al.(1990), Papageorgiou et al.(1991)]). Numerous variants have been published (see, e.g, [Papamichail et al.(2008), Smaragdis et al.(2003), Smaragdis et al.(2004)], and the references therein).

${ }^{1}$ ALINEA is an acronym of the French words: Asservissement LINéaire d'Entrée Autoroutière. 
The classic backward difference scheme

$$
\frac{x(t)-x(t-h)}{h} \approx \dot{x}(t)
$$

where

- $x$ is a differentiable time function,

- $h>0$ is small enough,

tells us, according to Equation (1), that ALINEA should be viewed as the discrete-time analogue of a pure integrator

$$
r(t)=k_{I} \int \varepsilon(\tau) d \tau
$$

where

- $\varepsilon=\rho^{\star}-\rho_{s}$ is the tracking error,

- $k_{I}$ is a gain.

Call it an integral controller, or a I controller. It corresponds to the I term in a classic PID controller (see, e.g., [Åström et al.(2006), Åström et al.(2008), Lunze(2010), O'Dwyer(2009)]). Ramp metering control might be one of the very few occurrences, if not the only one, where satisfactory performances were obtained for such controllers, which are almost never utilized in practice.

\section{I, iP and PI controllers}

\subsection{A short review of model-free control}

\subsubsection{Generalities}

Full details on model-free control are given by [Fliess et al.(2013)]. Its usefulness in many situations, including severe nonlinearities and time-varying properties, has been demonstrated. The corresponding intelligent controllers are much easier to implement and to tune that the well known PIDs which are today the main tool in industrial control engineering (see, e.g., [Åström et al.(2006), Åström et al.(2008), Lunze(2010), O'Dwyer(2009)]). Model-free control has been successfully applied to a large variety of concrete case-studies:

- see the references in [Fliess et al.(2013)],

- since then see, e.g., [De Miras et al.(2013), Madoński et al.(2013), Xu et al.(2013), Agee et al.(2014), Thabet et al.(2014), Agee et al.(2015), Jama et al.(2015),

Lafont et al.(2015), MohammadRidha et al.(2015), Menhour et al.(2015), Roman et al.(2015), Schwalb Moraes et al.(2015), Taapák et al.(2015), d'Andréa-Novel et al.(2016), Bara et al.(2016), Tebbani et al.(2016)], ... .

Remark 3.1 It is well known that traffic flow modeling has been heavily influenced by the partial differential equations of fluid mechanics (see, e.g., [Lighthill et al.(1955)], [Kerner(2004), Treiber et al.(2013)]). Let us therefore emphasize the success of the model-free setting for the control of hydroelectric power plants ([Join et al.(2010a), Join et al.(2010b)]), where nonlinear partial differential equations from fluid mechanics are also often employed. 
This control strategy will nevertheless be summarized below for the sake of completeness.

\subsubsection{The ultra-local model}

The unknown global description of the plant, which is assumed for simplicity's sake to be SISO (single-input single output), is replaced by the ultra-local model:

$$
\dot{y}=F+\alpha u
$$

where:

- the control and output variables are respectively $u$ and $y$,

- the derivation order of $y$ is 1 like in most concrete situations,

- the constant $\alpha \in \mathbb{R}$ is chosen by the practitioner such that $\alpha u$ and $\dot{y}$ are of the same magnitude. Therefor $\alpha$ does not need to be precisely estimated.

The following comments might be useful:

- Equation (3) is only valid during a short time lapse. It must be continuously updated,

- $F$ is estimated via the knowledge of the control and output variables $u$ and $y$,

- F subsumes not only the unknown structure of the system, which most of the time will be nonlinear, but also any external disturbance.

\subsubsection{Intelligent controllers}

Close the loop with the following intelligent proportional-integral controller, or $i P I$,

$$
u=-\frac{F-\dot{y}^{*}+K_{P} e+K_{I} \int e}{\alpha}
$$

where:

- $e=y-y^{\star}$ is the tracking error,

- $K_{P}, K_{I}$ are the usual tuning gains.

When $K_{I}=0$, we obtain the intelligent proportional controller, or $i P$, which is here employed:

$$
u=-\frac{F-\dot{y}^{*}+K_{P} e}{\alpha}
$$

Combining Equations (3) and (5) yields:

$$
\dot{e}+K_{P} e=0
$$

where $F$ does not appear anymore. The tuning of $K_{P}$ is therefore straightforward. 


\subsubsection{Estimation of $F$}

Assume that $F$ in Equation (3) is "well" approximated by a piecewise constant function $F_{\text {est }}$. The estimation techniques below are borrowed from [Fliess et al.(2003), Fliess et al.(2008)]. ${ }^{2}$ Let us summarize two types of computations:

1. Rewrite Equation (3) in the operational domain (see, e.g., [Yosida(1984)]):

$$
s Y=\frac{\Phi}{s}+\alpha U+y(0)
$$

where $\Phi$ is a constant. We get rid of the initial condition $y(0)$ by multiplying both sides on the left by $\frac{d}{d s}$ :

$$
Y+s \frac{d Y}{d s}=-\frac{\Phi}{s^{2}}+\alpha \frac{d U}{d s}
$$

Noise attenuation is achieved by multiplying both sides on the left by $s^{-2}$, since integration with respect to time is a lowpass filter. It yields in the time domain the realtime estimate, thanks to the equivalence between $\frac{d}{d s}$ and the multiplication by $-t$,

$$
F_{\text {est }}(t)=-\frac{6}{\tau^{3}} \int_{t-\tau}^{t}[(\tau-2 \sigma) y(\sigma)+\alpha \sigma(\tau-\sigma) u(\sigma)] d \sigma
$$

where $\tau>0$ might be quite small. This integral may of course be replaced in practice by a classic digital filter.

2. Close the loop with the iP (5). It yields:

$$
F_{\text {est }}(t)=\frac{1}{\tau}\left[\int_{t-\tau}^{t}\left(\dot{y}^{\star}-\alpha u-K_{P} e\right) d \sigma\right]
$$

Remark 3.2 From a hardware standpoint, a real-time implementation of our intelligent controllers is also cheap and easy ([Join et al.(2013)]).

\subsection{PI and iP}

Consider the classic continuous-time PI controller

$$
u(t)=k_{p} e(t)+k_{i} \int e(\tau) d \tau
$$

A crude sampling of the integral $\int e(\tau) d \tau$ through a Riemann sum $\mathcal{I}(t)$ leads to

$$
\int e(\tau) d \tau \simeq \mathcal{I}(t)=\mathcal{I}(t-h)+h e(t)
$$

where $h$ is the sampling interval. The corresponding discrete form of Equation (8) reads:

$$
u(t)=k_{p} e(t)+k_{i} \mathcal{I}(t)=k_{p} e(t)+k_{i} \mathcal{I}(t-h)+k_{i} h e(t)
$$

\footnotetext{
${ }^{2}$ See also the excellent recent book by [Sira-Ramírez et al.(2014)]. Let us add that those techniques are also used by [Abouaïssa et al.(2016)] for traffic flow forecast.
} 
Combining the above equation with

$$
u(t-h)=k_{p} e(t-h)+k_{i} \mathcal{I}(t-h)
$$

yields

$$
u(t)=u(t-h)+k_{p}(e(t)-e(t-h))+k_{i} h e(t)
$$

Remark 3.3 A trivial sampling of the "velocity form" of Equation (8)

$$
\dot{u}(t)=k_{p} \dot{e}(t)+k_{i} e(t)
$$

yields

$$
\frac{u(t)-u(t-h)}{h}=k_{p}\left(\frac{e(t)-e(t-h)}{h}\right)+k_{i} e(t)
$$

which is equivalent to Equation (9).

Replace in Equation (5) $F$ by $\dot{y}(t)-\alpha u(t-h)$ and therefore by

$$
\frac{y(t)-y(t-h)}{h}-\alpha u(t-h)
$$

It yields

$$
u(t)=u(t-h)-\frac{e(t)-e(t-h)}{h \alpha}-\frac{K_{P}}{\alpha} e(t)
$$

FACT.- Equations (9) and (11) become identical if we set

$$
k_{p}=-\frac{1}{\alpha h}, \quad k_{i}=-\frac{K_{P}}{\alpha h}
$$

Remark 3.4 This path breaking result was first stated by [d'Andréa-Novel et al.(2010)]:

- It is straightforward to extend it to PIDs.

- It explains apparently for the first time the ubiquity of PIs and PIDs in the industrial world, thanks to the properties of model-free control and of its associated intelligent controllers.

Remark 3.5 The previous equivalence, which is based on crude samplings, is however unable to deal with the unavoidable corrupting noises. When taking into account the estimation of $F$ in Equation (3) by the integral formula (7), i.e., by a lowpass filter, noises are attenuated. Formulae (12) may thus be replaced by

$$
k_{p}=-\frac{1}{\alpha h f_{c}}, \quad k_{i}=-\frac{K_{P}}{\alpha h f_{c}}
$$

where $f_{c}=20$. In signal processing $h f_{c}=20 h$ is known as the settling time (see, e.g., [Bellanger(2012), Proakis et al.(2007)]). 


\subsection{ALINEA and iP}

Equation (10) shows that on one hand ALINEA and I controllers, and on the other hand PI controllers are close when

1. $\dot{e}$ remains small,

2. the reference trajectory $y^{*}$ starts at the initial condition $y(0)$ or, at least, at a point which is very close to it,

3. the measurement noise corruption is low.

The second item mimics the rôle of reference trajectories in flatness-based control (see [Fliess et al.(1995)], and [Åström et al.(2008), Lévine(2009), Sira-Ramírez et al.(2004)]). The third item is due to the approximation of the derivative by an elementary Euler difference scheme. In the first item $\dot{e}$ remains small if the the reference trajectory is "slowly" varying, and if the disturbances and the corrupting noises are rather mild. From the equivalence depicted in Section 3.2, the performances of the ALINEA feedback loop (1) and of the iP controller (5) are also close if the above conditions are fulfilled, i.e.,

- the reference trajectory $y^{*}$ is "slowly" varying, and starts at the initial condition $y(0)$ or, at least, at a point which is quite close to it,

- the disturbances and the corrupting noises are rather mild.

According to the numerous successful applications of our intelligent controllers (see Section 3.1.1), the results provided by ALINEA should be satisfactory.

\section{Computer experiments}

\subsection{A first comparison between ALINEA and iP's via traf- fic computer simulations}

\subsubsection{METANET and traffic computer simulations: a quick look}

An extensive literature has been published in order to achieve "good" traffic computer simulations for highways. For this most difficult problem, a paper by [Lighthill et al.(1955)] played a prominent rôle and had a lasting influence. Among the various traffic modelings which have been deduced (see, e.g., [Hoogendoom et al.(2001)]), we selected METANET (see, e.g., [Messmer et al.(1990), Papageorgiou et al.(2010)]), which might be the most popular and efficient set of equations (see, e.g., [Spiliopoulou et al.(2014)]). Let us nevertheless emphasize that quick and significant changes in traffic dynamics are difficult to catch with it.

Remark 4.1 Other methodologies are possible, of course, like, for instance, neural networks (see, e.g., [Srinivasan et al.(2006)]).

\subsubsection{Implementation and results}

Our computer simulations are based on numerical data which are collected from the French highway A4Y with one on-ramp (see Figures 2 and 3-(a)). The 


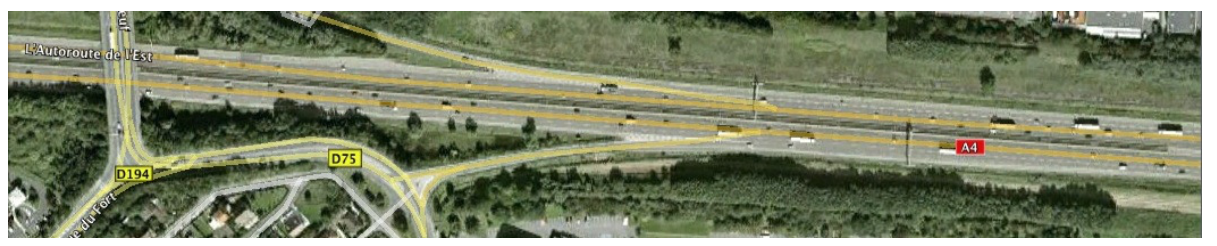

Figure 2: Aerial picture of the studied site (from DiRIF)

behaviors we are simulating are rather tame according to Section 4.1.1. To the best of our knowledge, clear-cut rules for the tuning of $K_{I}$ in Equation (1) have never been published. Several attempts lead us to $K_{I}=0.5$, which seems to be an excellent choice. For the iP controller (5) select, according to Section 3.1.2 (see also [Fliess et al.(2013)]),

- $\alpha=10$ such that the three terms in Equation (5) are of the same order of magnitude,

- $K p=5$ such that the dynamics of the tracking error given by Equation (6) exhibits a nice behavior.

Moreover $0.375 \leq r \leq 0.875$. In both cases $r$ is saturated. For ALINEA an antiwindup algorithm is necessary (see, e.g., [Åström et al.(2006), Åström et al.(2008), Lunze(2010), O'Dwyer(2009)]). An iP does not need it, since there is no integral term. Figures 3 and 4 present the results. The critical density in Figure 3 -(c) is a most important and classical quantity in traffic studies (see, e.g., [Kerner(2004)], and the references therein). The performances of the two control laws are very similar.

Remark 4.2 Let us stress the two following major features:

1. The total time spent during congestions is drastically reduced by both approaches (see Figure 4).

2. The queue length is ignored in the previous simulations for simplicity's sake.

\subsection{A non-linear academic example}

Consider the unstable non-linear system

$$
\dot{y}-y=u^{3}
$$

It is corrupted by an additive normal noise with a standard deviation equal to 0.03. Its behavior is more "violent" than those which were possible to simulate in Section 4.1.2 via METANET. Figure 5 is reproducing the excellent performances, already displayed in ([Fliess et al.(2013)]), for the iP (5) with $\alpha=1, K_{P}=2.2727$. The PI is given thanks to Formulae (13) and to $h=0.01 \mathrm{~s}$ by $k_{p}=-5, k_{i}=-11.3635$. Its performances, according to Figure 5 , are quite close to those of the iP. Figure 6 shows however that the corresponding I controller, where $k_{i}=-11.3635$, turns out to be highly fluctuating. The superiority of the iP and PI controllers with respect to the I controller becomes indisputable. 


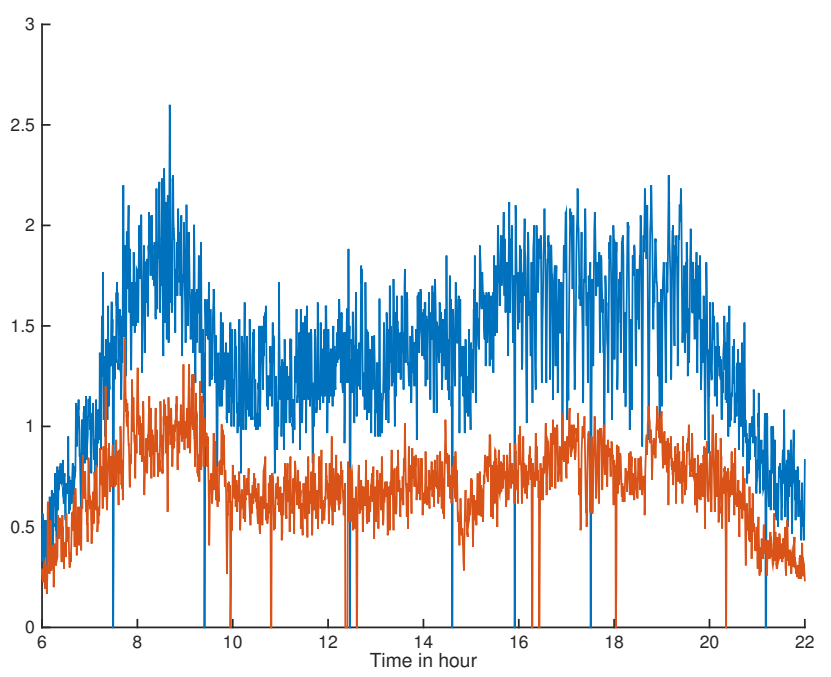

(a) Traffic demands in veh/s: on the ramp $(-$, red $)$ and the medium $(-$, blue $)$

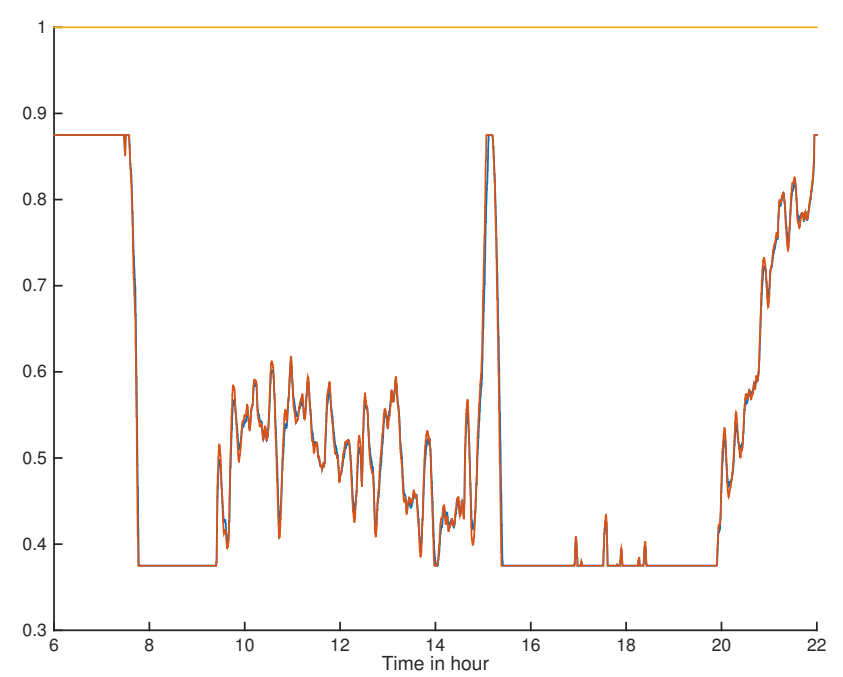

(b) Control rate : without control (-,yellow), iP (-,blue), ALINEA (-,red)

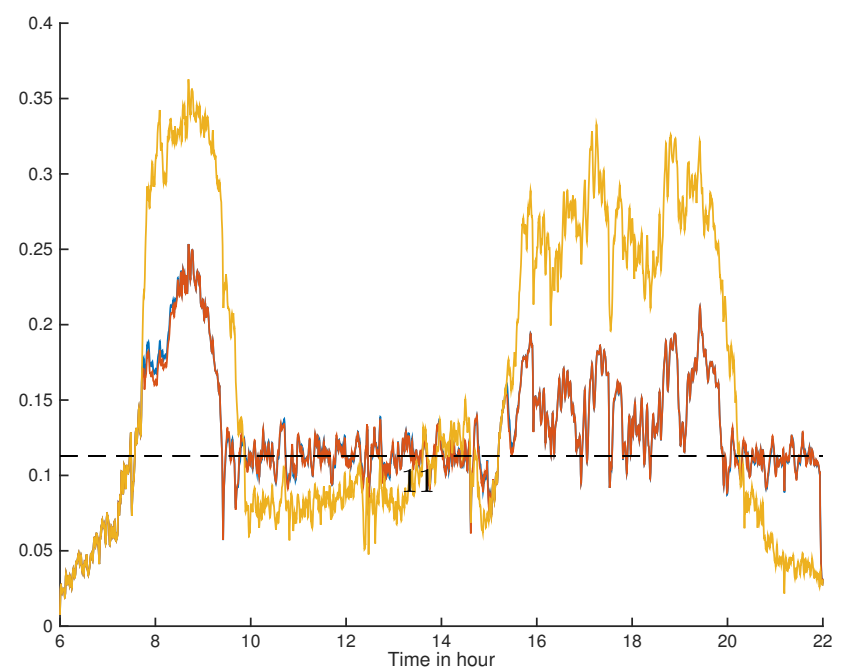

(c) Critical density in veh/m (- -, black), density without control (-,yellow), with iP (-,blue), with ALINEA (-,red) 


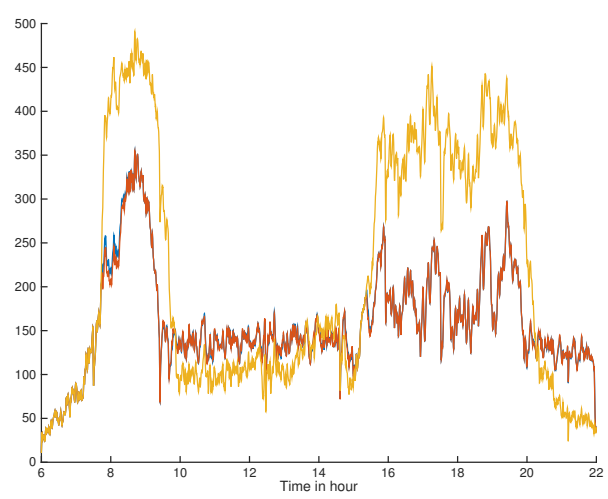

Figure 4: Total time spent in veh/s without control (-, yellow), with iP (-, blue), with ALINEA (-, red)

\section{Conclusion}

We have demonstrated, perhaps for the first time, why the performances of the feedback loop ALINEA for ramp metering control are "good", at least when the traffic conditions are "more or less smooth." The behaviours of

- ALINEA,

- the intelligent proportional controller stemming from model-free control,

- the corresponding classic PI controller,

are then quite close. When the traffic conditions become rougher, theory and preliminary digital simulations indicate that the results of the intelligent controllers become much superior. Let us emphasize nevertheless that those conclusions ought to be confirmed via practical implementations, where the queue length ought to be taken into account.

It is well known that tedious calibrations are requested for the practical implementation of any feedback loop for ramp metering. ${ }^{3}$ It has been demonstrated by [Join et al.(2015)] that those complex calculations, which are most difficult to achieve in real-time, may be bypassed for ALINEA. The proof mimics a similar and earlier result obtained for iPs by [Abouaïssa et al.(2012)]. Those facts will play a key rôle for concrete experiments.

\footnotetext{
${ }^{3}$ The critical density, which was already mentioned in Section 4.1 .2 , certainly is the most crucial quantity to be estimated.
} 


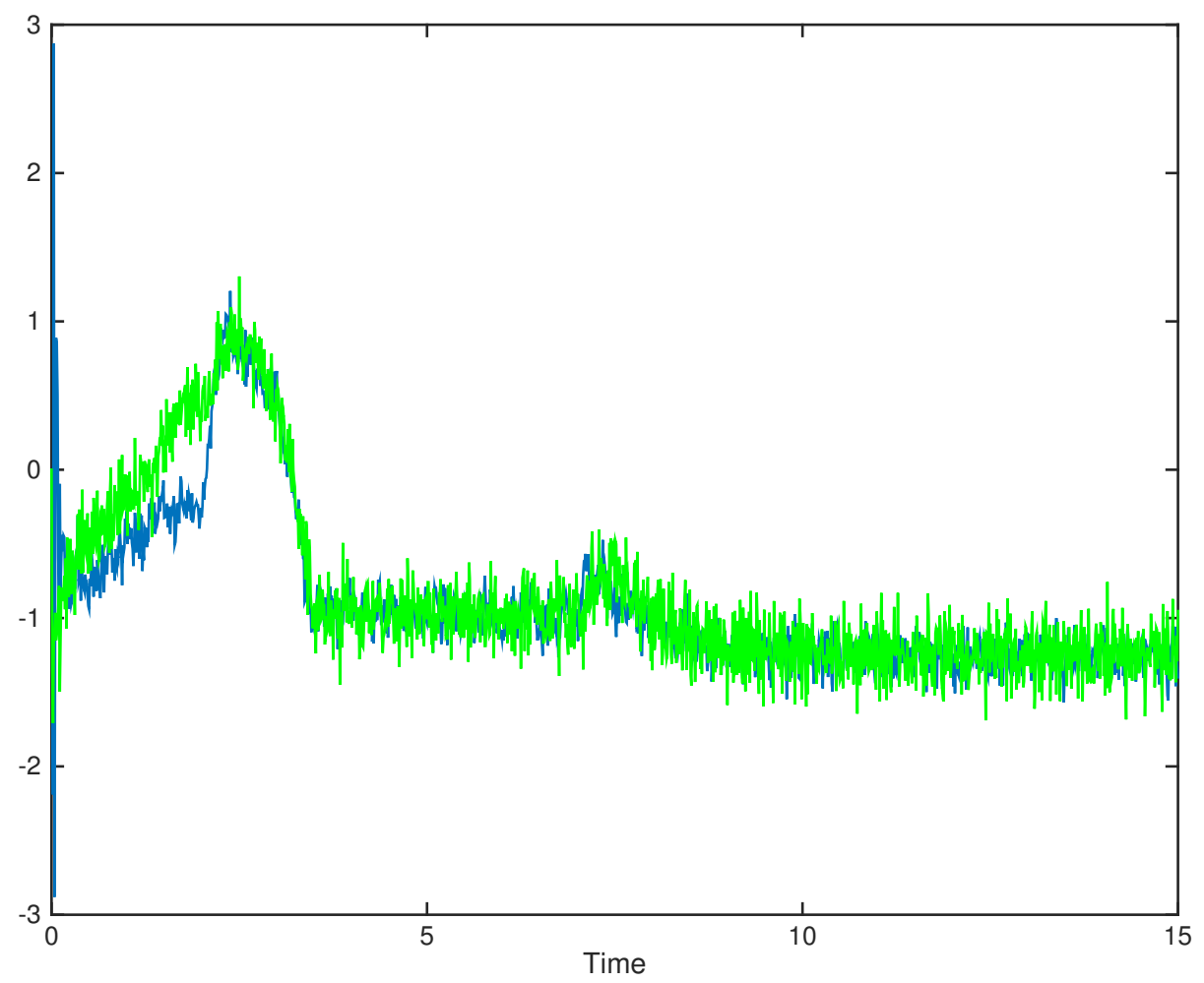

(a) Controls: iP(-, blue), PI(-, green)

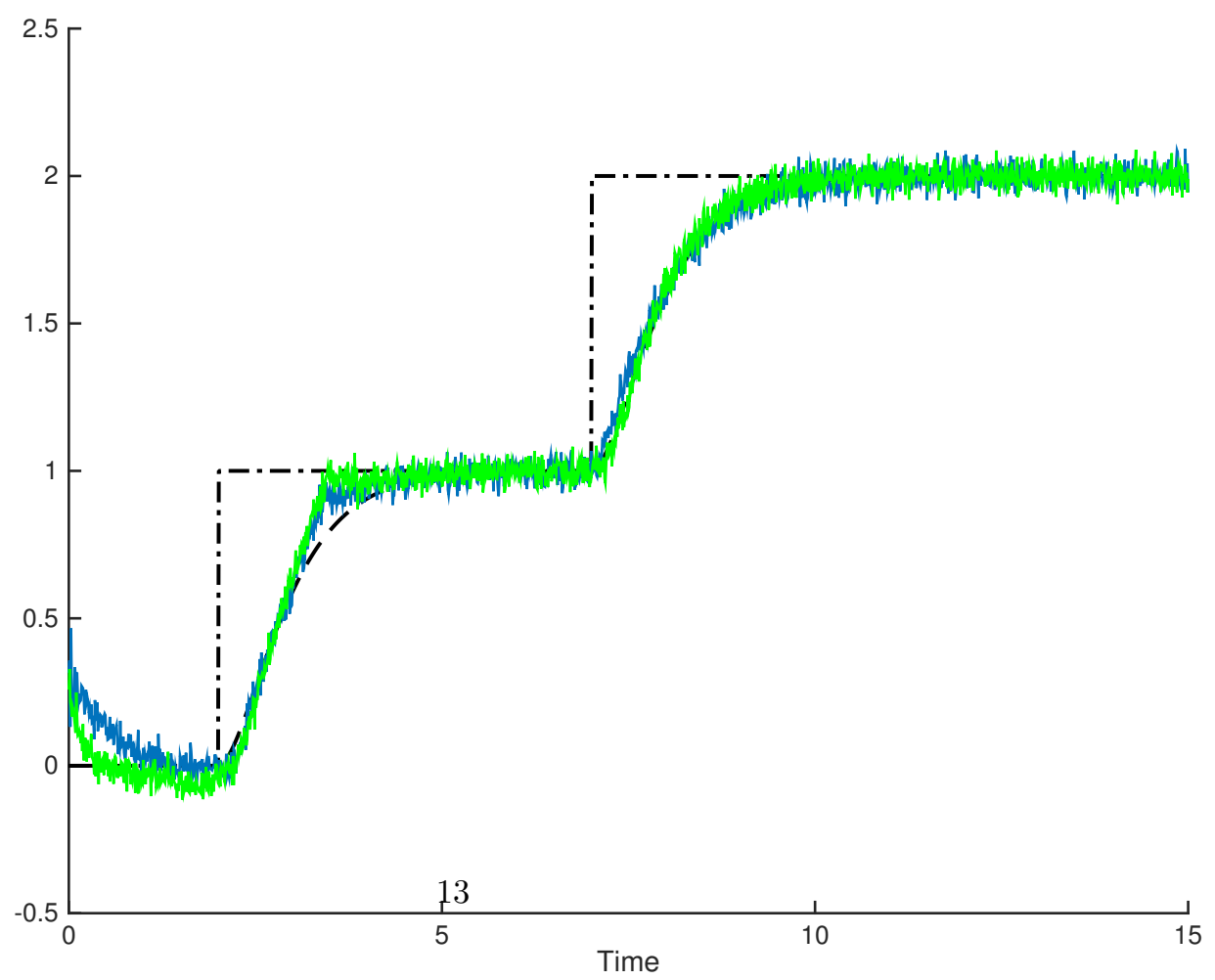

(b) Setpoint (- ,, black), reference (- -, black), and outputs: iP(-, blue), PI(-, green)

Figure 5: Non-linear system: comparisons 


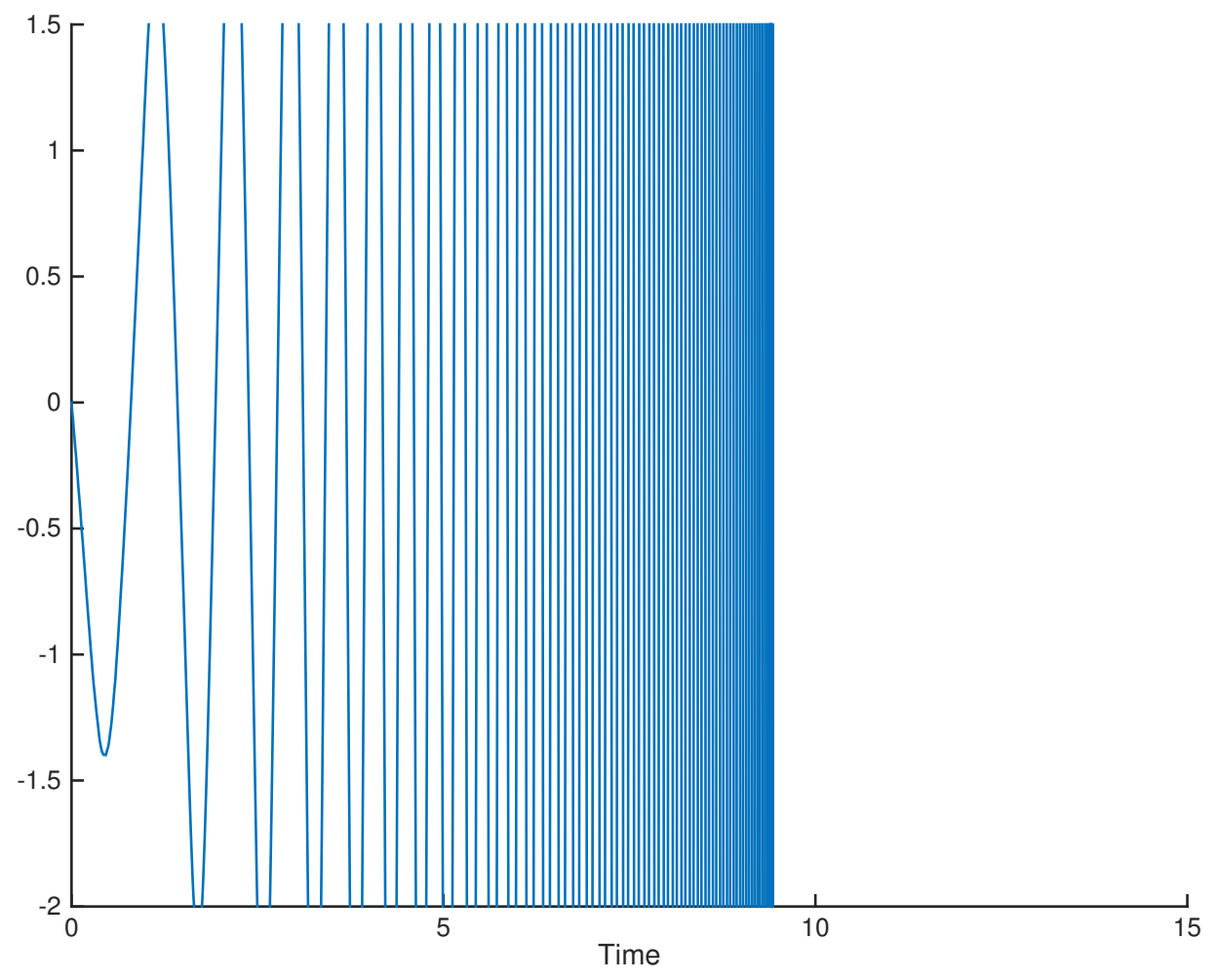

(a) Controls I

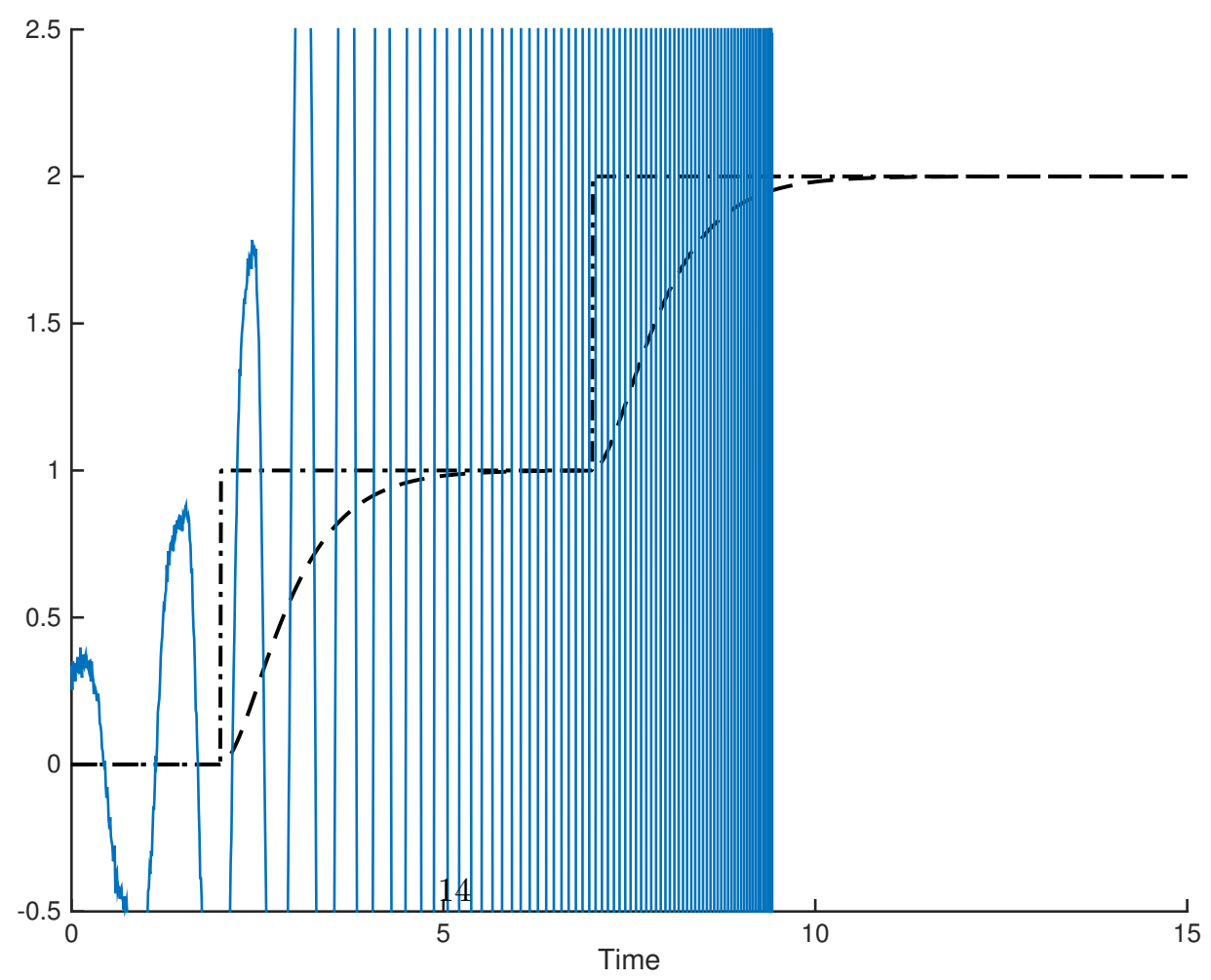

(b) Setpoint (- ., black), reference (- -, black), and outputs I

Figure 6: Non-linear system: comparisons 


\section{References}

[Abouaïssa et al.(2012)] Abouaïssa, H., Fliess, M., Iordanova, V., Join, C. (2012). Freeway ramp metering control made easy and efficient. 13th IFAC Symp. Control Transportation Systems, Sofia. Retrieved from https://hal .archives-ouvertes.fr/hal-00711847/en/

[Abouaïssa et al.(2016)] Abouaïssa, H., Fliess, M., Join, C. (2016). On shortterm traffic flow forecasting and its reliability. 8th IFAC Conf. Manufact. Model. Manag. Contr., Troyes, 2016. Retrieved from https://hal .archives-ouvertes.fr/hal-01275311/en/

[Agarwal et al.(2015)] Agarwal, S., Kachroo, P., Contreras, S., Sastry, S. (2015). Feedback-coordinated ramp control of consecutive on-ramps using distributed modeling and Godunov-based satisfiable allocation. IEEE Trans. Intel. Transport. Syst., 16, 2384-2392.

[Agee et al.(2014)] Agee, J.T., Bingul, Z., Kizir, S. (2014). Tip trajectory control of a flexible-link manipulator using an intelligent proportional integral (iPI) controller. Trans. Instit. Measur. Contr., 36, 673-682.

[Agee et al.(2015)] Agee, J.T., Kizir, S., Bingul, Z. (2015). Intelligent proportional-integral (iPI) control of a single link flexible joint manipulator. J. Sound Vibrat., 21, 2273-2288.

[d'Andréa-Novel et al.(2010)] d'Andréa-Novel, B., Fliess, M., Join, C., Mounier, H., Steux, B. (2010). A mathematical explanation via "intelligent" PID controllers of the strange ubiquity of PIDs. 18th Medit. Conf. Control Automat., Marrakech. Retrieved from https://hal .archives-ouvertes.fr/inria-00480293/en/

[d'Andréa-Novel et al.(2016)] d'Andréa-Novel, B., Menhour, L., Fliess, M., Mounier, H. (2016). Some remarks on wheeled autonomous vehicles and the evolution of their control design. 9th IFAC Symp. Intel. Autonom. Vehicl., Leipzig, 2016. Retrieved from

https://hal .archives-ouvertes.fr/hal-01294825/en/

[Åström et al.(2006)] Åström, K.J., Hägglund, T. (2006). Advanced PID Control. Instrument Soc. America.

[Åström et al.(2014)] Åström, K.J., , Kumar, P.R. (2014). Control: A perspective. Automatica, 50, 3-43.

[Åström et al.(2008)] Åström, K.J., Murray, R.M. (2008). Feedback Systems: An Introduction for Scientists and Engineers. Princeton University Press.

[Bara et al.(2016)] Bara, O., Fliess, M., Join, C., Day, J., Djouadi, S.M. (2016). Model-free immune therapy: A control approach to acute inflammation. Europ. Contr. Conf., Aalborg, 2016. Retrieved from https://hal .archives-ouvertes.fr/

[Bellanger(2012)] Bellanger, M. (2012). Traitement numérique du signal (9e éd.). Dunod. 
[De Miras et al.(2013)] De Miras, J., Join, J., Fliess, M., Riachy, S., Bonnet S. (2013). Active magnetic bearing: A new step for model-free control. 52nd IEEE Conf. Decision Control, Florence. Retrieved from https://hal.archives-ouvertes.fr/hal-00857649/en/

[Fliess et al.(2013)] Fliess, M., Join, C. (2013). Model-free control. Int. J. Control, 86, 2228-2252.

[Fliess et al.(1995)] Fliess, M., Lévine, J., Martin, P., Rouchon, P. (1995). Flatness and defect of non-linear systems: introductory theory and examples. Int. J. Control, 61, 1327-1361.

[Fliess et al.(2003)] Fliess, M., Sira-Ramírez, H. (2003). An algebraic framework for linear identification. ESAIM Control Optimiz. Calc. Variat., 9, 151-168.

[Fliess et al.(2008)] Fliess, M., Sira-Ramírez, H. (2008). Closed-loop parametric identification for continuous-time linear systems via new algebraic techniques. H. Garnier, L. Wang (Eds): Identification of Continuous-time Models from Sampled Data, Springer, pp. 362-391.

[Gao(2014)] Gao, Z. (2014). On the centrality of disturbance rejection in automatic control. ISA Trans., 53, 850-857.

[Haj-Salem et al.(1988)] Haj-Salem, H., Blosseville, J.-M., Davée, M.M., Papageorgiou, M. (1988). ALINEA: Un outil de régulation d'accès isolé sur autoroute - Étude comparative sur site réel. Rapport INRETS $n^{\circ}$ 80, Arcueil.

[Haj-Salem et al.(1990)] Haj-Salem, H., Blosseville, J.-M., Papageorgiou, M. (1990). ALINEA - a local feedback control law for on-ramp metering: a real life study. 3rd IEE Intern. Conf. Road Traffic Control, London, pp. 194-198.

[Hoogendoom et al.(2001)] Hoogendoorn, S.P., Bovy, P.H. (2001). State-of-theart of vehicular traffic flow modelling. Proc. Inst. Mech. Eng. 215, 283-303.

[Jama et al.(2015)] Jama, M.A., Noura, H., Wahyudie, A., Assi, A. (2015). Enhancing the performance of heaving wave energy converters using modelfree control approach. Renew. Energy, 83, 931-941.

[Join et al.(2015)] Join, C., Abouaïssa, H., Fliess, M. (2015). A fresh look at ramp metering control: ALINEA without any tedious calibration. Research Rep., École polytechnique, Palaiseau. Retrieved from https://hal archives-ouvertes.fr/hal-01117068/en/

[Join et al.(2013)] Join, C., Chaxel, F., Fliess, M. (2013). "Intelligent" controllers on cheap and small programmable devices. 2nd Int. Conf. Control Fault-Tolerant Syst., Nice. Retrieved from https://hal . archives-ouvertes.fr/hal-00845795/en/

[Join et al.(2010a)] Join, C., Robert, G., Fliess, M. (2010a), Model-free based water level control for hydroelectric power plants, IFAC Conf. Control Method. Technologies Energy Efficiency, Vilamoura. Retrived from https://hal.archives-ouvertes.fr/inria-00458042/en/ 
[Join et al.(2010b)] Join, C., Robert, G., Fliess, M. (2010b), Vers une commande sans modèle pour aménagements hydroélectriques en cascade, $\sigma^{e}$ Conf. Internat. Francoph. Automat., Nancy. Retrieved from https://hal .archives-ouvertes.fr/inria-00460912/en/

[Kachroo et al.(2003)] Kachroo, P., Ozbay, K. (2003). Feedback Ramp Metering in Intelligent Transportation Systems. Springer.

[Kerner(2004)] Kerner, B.S. (2004). The Physics of Traffic. Springer.

[Lafont et al.(2015)] Lafont, F., Balmat, J.-F., Pessel, N., Fliess, M. (2015). A model-free control strategy for an experimental greenhouse with an application to fault accommodation. Comput. Electron. Agricult., 110, 139-149.

[de Larminat(2009)] de Larminat, P. (2009). Automatique appliquée (2e éd.). Hermès-Lavoisier, 2009.

[Lévine(2009)] Lévine, J. (2009). Analysis and Control of Nonlinear Systems A flatness-based approach. Springer.

[Lighthill et al.(1955)] Lighthill, M.J., Whitham, G.B. (1955). On kinematic waves II: A theory of traffic flow in long crowded roads. Proc. Royal Soc. London, A-229, 317-345.

[Lunze(2010)] Lunze, J. (2010). Regelungstheorie 1 (8. Auflage). Springer.

[Madoński et al.(2013)] Madoński, R., P. Herman, P. (2013). Model-free control of a two-dimensional system based on uncertainty reconstruction and attenuation. 2nd Int. Conf. Contr. Fault-Tolerant Syst., Nice, 2013.

[Mammar(2007)] Mammar, S. (Ed.) (2007). Systèmes de transport intelligents : Modélisation, information et contrôle. Hermès-Lavoisier.

[Menhour et al.(2015)] Menhour, L., d'Andréa-Novel, B., Fliess, M., Gruyer, D., Mounier, H. (2015). A new model-free design for vehicle control and its validation through an advanced simulation platform. 14th Europ Control Conf., Linz. Retrieved from https://hal archives-ouvertes.fr/hal-01134599/en/

[Messmer et al.(1990)] Messemer, A., \& Papageorgiou, M. (1990). Metanet: a macroscopic simulation program for motorway networks. Traffic Engin. Contr., 31, 446-470.

[MohammadRidha et al.(2015)] MohammadRidha, T., Moog, C.H., Delaleau, E., Fliess, M., Join, C. (2015). A variable reference trajectory for modelfree glycemia regulation. SIAM Conf. Control Appl., Paris. Retrieved from https://hal .archives-ouvertes.fr/hal-01141268/en/

[O'Dwyer(2009)] O'Dwyer, A. (2009). Handbook of PI and PID Controller Tuning Rules (3rd ed.). Imperial College Press.

[Papageorgiou et al.(2003)] Papageorgiou, M., Diakaki, C., Dinopoulou, D., Kostialos, A., Wang, Y. (2003). Review of road traffic control strategies. IEEE Trans. Intel. Transport. Syst., 91, 2043-2067. 
[Papageorgiou et al.(1991)] Papageorgiou, M., Hadj-Salem, H., Blosseville, J.M. (1991). ALINEA: A local feedback control law for on-ramp metering, Transp. Res. Record, $n^{\circ}$ 1320, 58-64.

[Papageorgiou et al.(2007)] Papageorgiou, M., Kosmatopoulos, E., Papamichail, I., Wang, Y. (2007). ALINEA maximises motorway throughput - An answer to flawed criticism. Traffic Engin. Contr., 48, 271-276.

[Papageorgiou et al.(2010)] Papageorgiou, M., Papamichail, I., Messmer, A., Wang, Y. (2010). Traffic simulation with METANET. J. Barceló, Ed.: Fundamentals of Traffic Simulation, Springer.

[Papamichail et al.(2008)] Papamichail, I., Papageorgiou, M. (2008) Trafficresponsive linked ramp-metering control, IEEE Trans. Intel. Transport. Syst., 9, 111-121.

[Proakis et al.(2007)] Proakis, J.G., \& Manolakis, D.K. (2007). Digital Signal Processing. Prentice Hall.

[Roman et al.(2015)] Roman, R.-C., Radac, M.-B., Precup, R.-E., Petriu, E.M. (2015). Data-driven optimal model-free Control of twin rotor aerodynamic systems. IEEE Int. Conf. Industr. Techno., Seville.

[Schwalb Moraes et al.(2015)] Schwalb Moraes, M., Pereira da Silva, P.S. (2015). Model-free control of magnetic levitation systems through algebraic derivative estimation, 23rd ABCM Int. Congr. Mechan. Engin, Rio de Janeiro, 2015.

[Sira-Ramírez et al.(2004)] Sira-Ramírez, H., Agrawal, S. (2004). Differentially Flat Systems. Marcel Dekker.

[Sira-Ramírez et al.(2014)] Sira-Ramírez, H., García-Rodríguez, C., CortèsRomero, J., Luviano-Juárez, A. (2014). Algebraic Identification and Estimation Methods in Feedback Control Systems. Wiley.

[Smaragdis et al.(2003)] Smaragdis, E., Papageorgiou, M. (2003). A series of new local ramp metering strategies. Transport. Res. Record: J. Transport. Res. Board, 1856, 74-86.

[Smaragdis et al.(2004)] Smaragdis, E., Papageorgiou, M., Kosmatopoulos, E. (2004). A flow-maximizing adaptive local ramp metering strategy. Transport. Res. B, 38, 251-270.

[Spiliopoulou et al.(2014)] Spiliopoulou, A., Kontorinaki, M., Papageorgiou M., Kopelias, P. (2014). Macroscopic traffic flow model validation at congested freeway off-ramp areas. Transport. Res. C, 41, 18-29.

[Srinivasan et al.(2006)] Srinivasan, D., Choy, M.C., Cheu, R.L. (2006). Neural networks for real-time traffic signal control. IEEE Trans. Intel. Transport. Syst., 7, 261-272.

[Ťapák et al.(2015)] Ťapák, P., Huba, M. (2015). Intelligent P controller and disturbance observer based PI controller comparison. 2015 Int. Conf. Process Control, Štrbské Pleso. 
[Tebbani et al.(2016)] Tebbani, S., Titica, M., Join, C., Fliess, M., Dumur, D. (2016). Model-based versus model-free control designs for improving microalgae growth in a closed photobioreactor: Some preliminary comparisons. 24th Medit. Conf. Contr. Automat., Athens, 2016. Retrieved from https://hal .archives-ouvertes.fr/hal-01312251/en/

[Thabet et al.(2014)] Thabet, H., Ayadi, M., Rotella, F. (2014). Towards an ultra-local model control of two-tank-system. Int. J. Dyn. Contr., DOI $10.1007 / \mathrm{s} 40435-014-0105$

[Treiber et al.(2013)] Treiber, M., Kesting, A. (2013). Traffic Flow Dynamics. Springer.

[Xu et al.(2013)] Xu, Y., Bideaux, É, Thomasset, D (2013). Robustness study on the model-free control and the control with restricted model of a high performance electro-hydraulic system. 13th Scandin. Int. Conf. Fluid Power, Linköping, 2013.

[Yosida(1984)] Yosida K. (1984), Operational Calculus (translated from the Japanese), Springer. 